BIOMEDICA

Vol. 4 , No. 3 y $4-1984$

\title{
ENTERITIS HEMORRAGICA POR ADENOVIRUS EN PAVOS
}

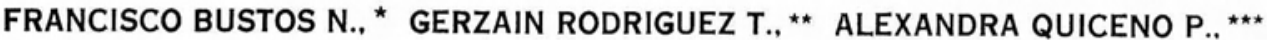 \\ NESTOR A. MOSSOS C.. * YOLANDA DE NAVAS. *
}

Se describe por primera vez en Colombia la enteritis hemorrágica (EH), en pavos de 4 a 11 semanas de edad, mediante estudios macroscópicos, histológicos y de microscopía electrónica. Se demostró una enteritis hemorrágica severa, y esplenomegalia con inclusiones intranucleares en la mayoría de las células de la pulpa blanca esplénica y en algunos mononucleares en el intestino delgado. Las inclusiones son características; consisten de un centro eosinofilico, rodeado de cromatina densa y condensada sobre la membrana nuclear y de una estructura muy basófila y densa sobre un polo nuclear que parece corresponder a un nucleolo. Al microscopio electrónico se aprecian fases del desarrollo viral, desde un material filamentoso y amorfo hasta la formación de grandes acúmulos de viriones y cápsides de 70-80 $\mathrm{nm}$ de diámetro con morfología típica de adenovirus. Los viriones se demostraron fácilmente en macerados de bazo fijado en formol, teñidos negativamente con fosfotungstato de potasio; no se visualizaron en el contenido intestinal hemorrágico estudiado con el mismo método. El estudio de microscopía de luz de bazo e intestino es suficiente para establecer el diagnóstico de esta entidad.

\section{INTRODUCCION}

La enteritis hemorrágica (EH) es una enfermedad viral infectocontagiosa que ocasiona graves pérdidas económicas en planteles avícolas destinados a la explotación de pavos.

En Colombia se han observado algunos casos de $\mathrm{EH}$ aviar en los últimos meses (1), que han sido confundidos con coccidiosis o micotoxicosis por los usuarios, entidades con clínica semejante a la EH. Por ser el Laboratorio de Investigaciones Médicas Veterinarias, LIMV, el laboratorio nacional de referencia para la especie aviar, se adelantó la presente investigación, con el fin de precisar si la entidad observada correspondía en realidad a la EH viral descrita en la literatura foránea. Los estudios realizados comprueban la existencia en Colombia de la EH de los pavos producida por adenovirus. Como la entidad no es bien conocida en nuestro medio, presentamos una revisión de sus características generales.

La $\mathrm{EH}$ es una enfermedad viral aguda, que afecta pavos mayores de cuatro semanas de edad (2-4). Fue descrita por primera vez por Pomeroy y colaboradores en Minnessota (USA) en 1937 y posteriormente en otros estados en donde ha tenido caracteres epidémicos $(2,3,5,6)$. Se ha observado también en Canadá, Japón, Australia, India e Israel $(2,3,6)$. Puede

\footnotetext{
* Sección de Enfermedades Aviares, Instituto Colombiano Agropecuario. ICA. Apartado Aéreo 29743 Bogotá.

** Grupo de Patología, Instituto Nacional de Salud, INAS, Profesor Asociado Departamento de Patología, Facultad de Medicina, Universidad Nacional.

*** Grupo de Patología INAS.
} 
presentarse en forma aislada, con tendencia a persistir o infectar diferentes galpones de la misma granja, ocasionando pérdidas económicas importantes $(3,6)$. No existe evidencia de transmisión de esta entidad a otros animales 0 a los humanos $(3,6)$.

\section{ETIOLOGIA}

El agente etiológico es un adenovirus relacionado estrechamente con el de la enfermedad denominada "bazo de mármol de los faisanes" (MSD) (2,5,7). Tiene 70-80 nm de diámetro, con simetría icosahédrica, posee 252 capsómeros y una densidad de $1,34 \mathrm{~g} / \mathrm{ml}$ empleando gradientes de sucrosa $(2,5,8,9)$. Se replica en el núcleo de las células del sistema fagocítico mononuclear, primariamente del bazo, originando inclusiones intranucleares $(3,5,7)$. Se destruye a $70^{\circ} \mathrm{C}$ durante una hora, hipoclorito de sodio al $0,0086 \%$, Lysol al $1 \%$, Lauryl sulfato de sodio al 1\%, cloro y fenol. También por desecación a $37^{\circ} \mathrm{C}$ ó $25^{\circ} \mathrm{C}$. durante una semana. $(2,3)$.

Los intentos para propagar el virus en el laboratorio no han sido satisfactorios, empleando huevos embrionados o cultivos celulares de pavo o pollo $(2,10,11)$. Sin embargo, recientemente el virus pudo propagarse in vitro empleando una línea celular derivada de linfoblastos B $(10,11)$.

\section{PATOGENESIS}

Los pavos y faisanes son los únicos huéspedes naturales conocidos para este grupa de virus (EH-MSD) $(2,5)$.

La enfermedad se presenta entre las 6-12 semanas de edad; los recién nacidos y los animales menores de cuatro semanas, pueden infectarse pero no desarrollan signos clínicos $(12,13)$; la mortalidad varía entre el 1 y $60 \%$ de los animales enfermos. $(2,3,12,14)$.

El virus puede ser aislado de la cama, la materia fecal y las carcasas de pavos infectados $(2,3,5,6)$. La infección natural se adquiere posiblemente por vía oral $(2,3)$ y tiene un período de incubación de 6-10 días. Se puede producir la infección experimental inoculando virus por vía venosa o intracloacal, acortándose así el período de incubación a 3 ó 4 días $(2,3,6)$.

El virus se múltiplica en el sistema fagocítico mononuclear, originando lesiones y cuerpos de inclusión en el bazo, hígado, médula ósea e intestino principalmente $(3,15)$. Aunque la diarrea y la enteritis hemorrágica son las responsables de la muerte del animal, el bazo ha sido reconocido como el órgano blanco para la replicación viral (16).

La interrelación entre las lesiones esplénicas e intestinales no está bien dilucidada, $(2,16)$, pero se sabe que la presencia del bazo es necesaria para que se desarrollen las lesiones hemorrágicas intestinales (16).

\section{SIGNOS}

La enfermedad se presenta en forma súbita; las aves manifiestan depresión, anorexia y reducción en el consumo de agua; desde las primeras 24 horas se presenta melena y la mortalidad comienza entre 5-10 días de iniciada la enfermedad; algunos pavos mueren en forma súbita y otros muestran una rápida recuperación $(2,3,5,6)$.

\section{LESIONES}

Las lesiones se presentan en el intestino delgado y en el bazo, principalmente. En el primero se observa congestión y hemorragias masivas, con necrosis en las puntas de las vellosidades. El bazo es grande y presenta necrosis multifocal de los centros germinales.

Microscópicamente pueden apreciarse cuerpos de inclusión intranucleares característicos, en células histiocitarias del intestino, bazo, hígado y médula ósea $(2,3,5,6,12)$.

\section{DIAGNOSTICO DIFERENCIAL}

La entidad debe diferenciarse de la reticuloendoteliosis, producida por un retrovirus, en la cual se presenta esplenomegalia $\mathrm{y}$ hepatomegalia con infiltrados de tamaño variables en estos órganos; 
de infecciones bacterianas y de afecciones tóxicas por drogas o micotoxinas, que ocasionan enteritis hemorrágica similar a la observada en esta enfermedad, pero sin cuerpos de inclusión $(3,15)$.

En la EH pueden demostrarse anticuerpos precipitantes mediante la Prueba de inmunodifusión doble en agar, preparando el antígeno a partir de bazo de aves afectadas $(2,3,6)$ o por la prueba de ELISA $(14,17)$.

\section{INMUNIDAD}

Los pavos que se recuperan de la enfermedad tienen inmunidad específica de por vida $(2,3,6,12)$. La inmunidad pasiva puede adquirirse empleando suero de aves convalecientes $(2,3)$. También se han empleado vacunas preparadas a partir de extractos crudos de intestino o de bazo de pavos infectados con cepas avirulentas; algunas han dado buenos resultados; también se han utilizado cepas inactivadas de adenovirus productores de la enfermedad del "bazo de mármol de faisanes" $[3,18)$. Recientemente se ha preparado una vacuna propagando el virus en una línea de células linfoblásticas de enfermedad de Marek en pavos. Los pavos que recibieron esta vacuna no sufrieron la $\mathrm{EH}$ cuando se infectaron con una cepa virulenta de esta entidad (10).

\section{MATERIAL Y METODOS}

En diferentes galpones de una granja avícola se había presentado una enteritis hemorrágica en pavos de 4-11 semanas de edad, persistente durante junio-agosto de 1983 y enero -julio de 1984, con una mortalidad aproximada del $3.5 \%$. Sometimos a necropsia 24 de estos animales.

De las aves que presentaron minimos cambios post-morten, se tomaron muestras de todos los órganos que fueron fijados en formol tamponado al $10 \%$ y sometidos a proceso histológico usual. Además se guardaron muestras de intestino delgado en bolsas plásticas estériles.

Para tinción negativa se maceraron por separado pequeños fragmentos de bazo, de intestino delgado y de contenido hemorrágico intestinal, en PBS con Tween 20. Cada macerado se centrifugó a $3.000 \mathrm{rpm}$. por 10 minutos, seguido de centrifugación a $10.000 \mathrm{rpm}(15.600 \mathrm{~g})$ por 15 minutos. A partir del sedimento obtenido se realizaron tinciones negativas con fosfotunstato de $\mathrm{K}$ a $\mathrm{pH} 6,0$ en rejillas cubiertas con colodión, que se examinaron al microscopio electrónico a $\mathbf{5 0 . 0 0 0}$ aumentos.

Fragmentos de bazo, conservados por largo tiempo en formol tamponado, se post-fijaron en $\mathrm{OSO}_{4}$ y luego de deshidratación en alcoholes, se incluyeron en resinas epóxicas, para hacer cortes de una micra para análisis al microscopio de luz luego de teñirlos con azul de toluidina, y cortes finos que se contrastaron con acetato de uranilo e hidróxido de plomo y se examinaron con el microscopio electrónico.

\section{RESULTADOS}

\section{ESTUDIO MACROSCOPICO}

Las aves sometidas a necropsia en general presentaron buen estado de carnes; algunas sin embargo, mostraron palidez generalizada; el intestino delgado estaba aumentado de volumen principalmente el duodeno y el yeyuno, que eran de color oscuro y estaban fuertemente distendidos por un contenido de aspecto sanguinolento (Figura 1).

La mucuosa del duodeno y del yeyuno estaba congestionada, hemorrágica, con presencia de membranas fibrinosas. El tamaño del bazo estuvo aumentado aproximadamente al doble con respecto al de aves clínicamente sanas de la misma edad (Figura 2), y mostró focos blanquecinos subcapsulares. El corte reveló un tejido homogéneo parduzco, sin individualización de los nódulos linfoides.

\section{ESTUDIO MICROSCOPICO}

De todos los tejidos examinados, el bazo e intestino mostraron los cambios más sobresalientes (Figuras 1-7). No encontramos cambios significativos en hígado $y$ pulmón, encéfalo o riñón. No se examinó 


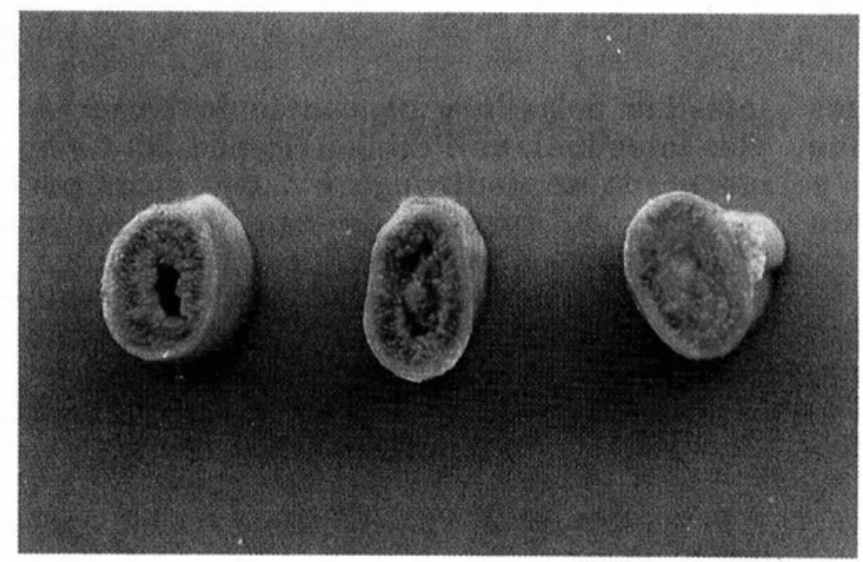

Fig. 1.

Engrosamiento e impregnación hemorrágica del duodeno.

Fig. 2.

Esplenomegalia. EI bazo de la izquierda es de un pavo normal.
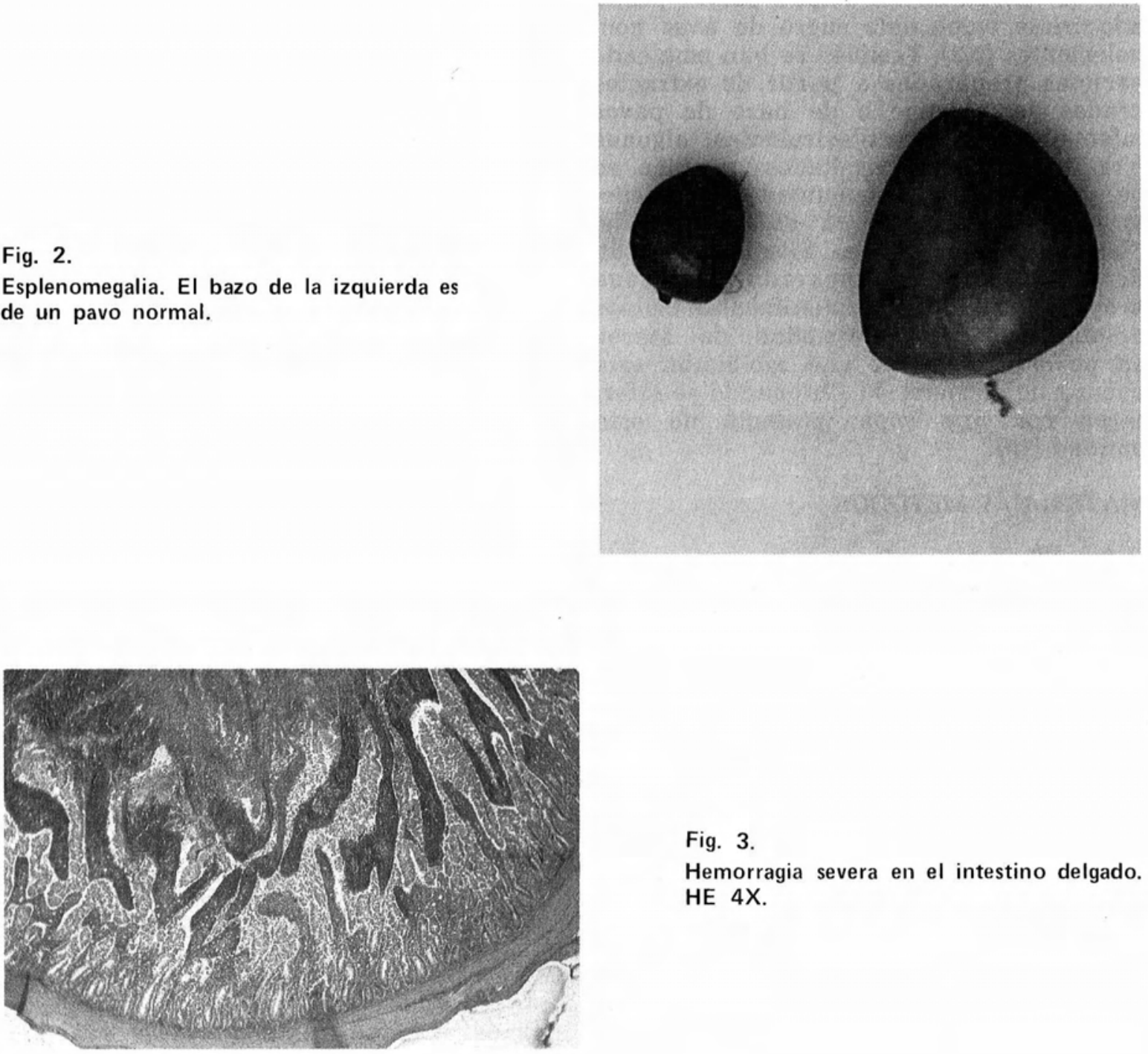

Fig. 3 .

Hemorragia severa en el intestino delgado. HE 4X. 


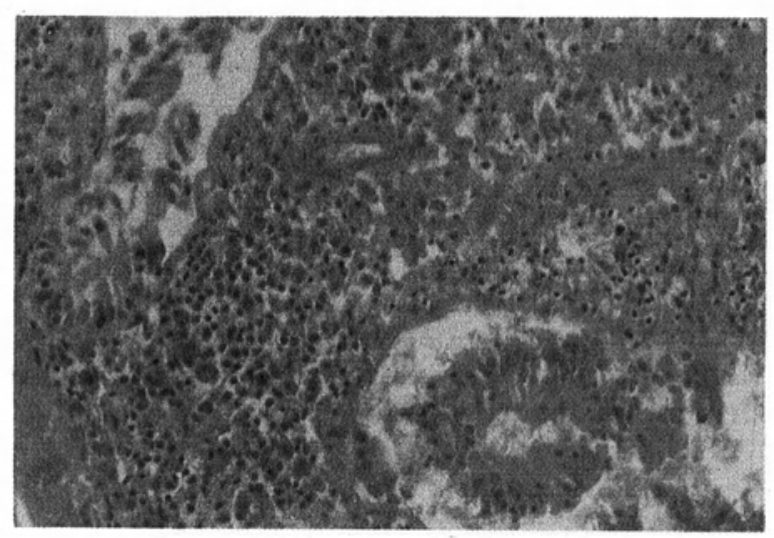

Fig. 4.

Inclusión intranuclear en células de la lámina propia del intestino delgado. HE 40X.

Fig. 5.

Bazo. Inclusiones intranucleares. H.E. $40 X$.
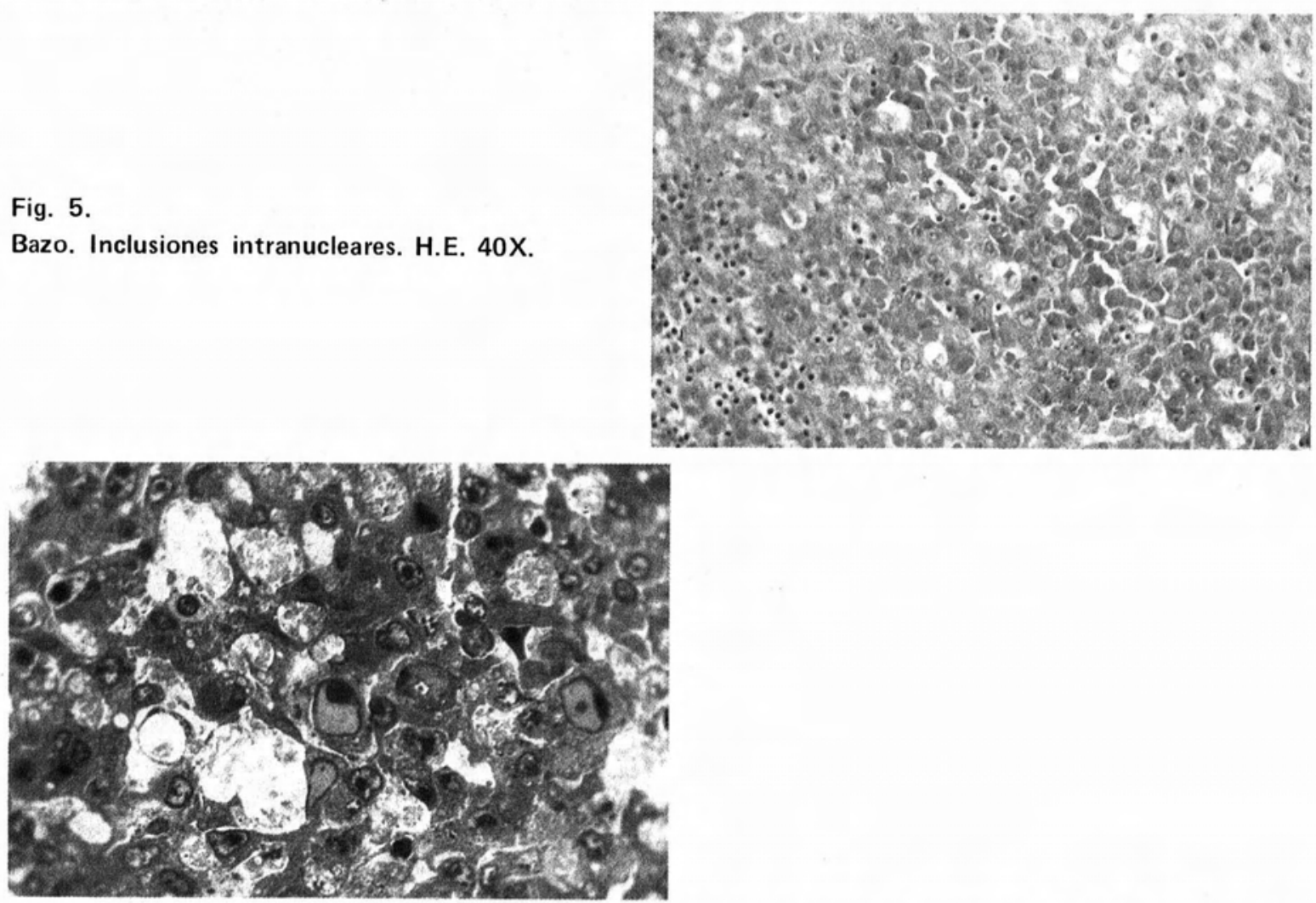

Figs. 6 y 7.

Bazo. Inclusiones intranucleares. Nótese la estructura periférica más densa que sugiere un nucléolo. Compárese con las figuras 10-13. Epon-Araldita. Azul de toluidina. $1000 \mathrm{X}$.

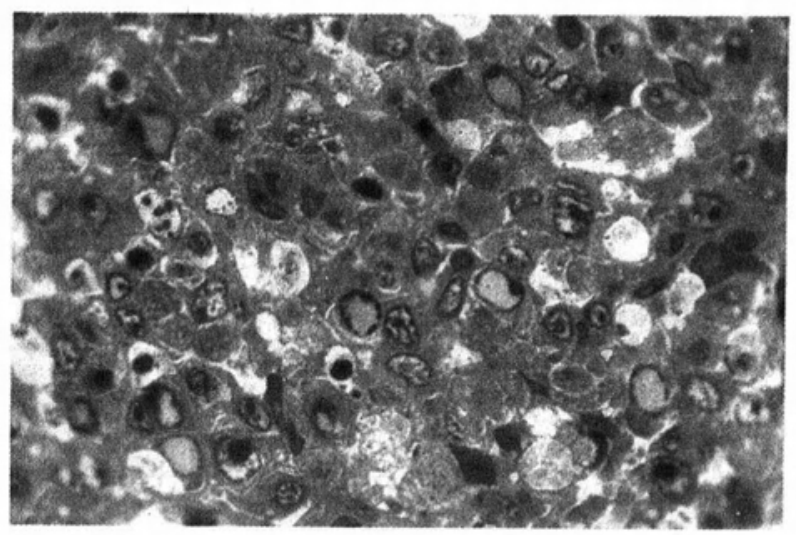


la médula ósea. En el lumen intestinal se observaron células epiteliales descamadas, sangre en proceso de digestión, abundantes bacterias y fibrina (Figura 3). En la lámina propria se vió infiltración masiva por plasmocitos, linfocitos, heterófilos e histiocitos. Algunos mononucleares presentaban típicas inclusiones intranucelares iguales a las que describiremos más adelante en el bazo (Figura 4). La hemorragia era masiva e impregnaba amplias zonas de la mucosa, respetando las capas musculares y la serosa que fueron normales (Figura 1).

Las lesiones esplénicas se caracterizaron depleción linfoide y abundancia de células histiocitarias, con inclusiones intranucleares en la gran mayoría de las células presentes, respetándose sólo las endoteliales, los eritrocitos, los linfocitos y algunas células claras periarteriales, de tal forma que cualquier corte del órgano es muy rico en inclusiones (Figura 5). Con la $\mathrm{HE}$ se ven claras, discretamente eosinófilas rechazando la cromatina hacia la membrana nuclear, de tal forma que el aspecto general del corte es pálido (Figura 5). Es frecuente que en uno de los polos nucleares con la cromatina rechazada, aparezca una zona nodular o en media luna, que se tiñe intensamente (Figura 5,7), aspecto que es más conspicuo en los cortes semifinos (Figuras 6,7). La imagen nos parece un nucleolo.

\section{MICROSCOPIA ELECTRONICA}

El macerado de bazo reveló abundantes partículas virales romboidales características de adenovirus (Figura 8) dispersas, aisladas e individuales. En el macerado de intestino y de su contenido no se demostraron adenovirus.

Todos los cortes gruesos de bazo revelaron gran cantidad de inclusiones intranucleares (Figuras 6,7). Al microscopio electrónico fue posible ver diferentes fases del desarrollo de esta inclusión (Figuras 9-18). En muchos núcleos se ven estructuras filamentosas, largas, que adoptan un aspecto en malla finamente cuadriculada, estriada, que en general no se acompaña de otros signos de infección viral (Figura 9), pero cuya frecuente presentación sugiere un primer signo ultraestructural de desarrollo del virus. En fases siguientes la cromatina nuclear se margina, el centro se hace más claro y es finamente granular y filamentoso (Figura 10). A veces estos núcleos contienen también la estructura filamentosa cristalina descrita antes.

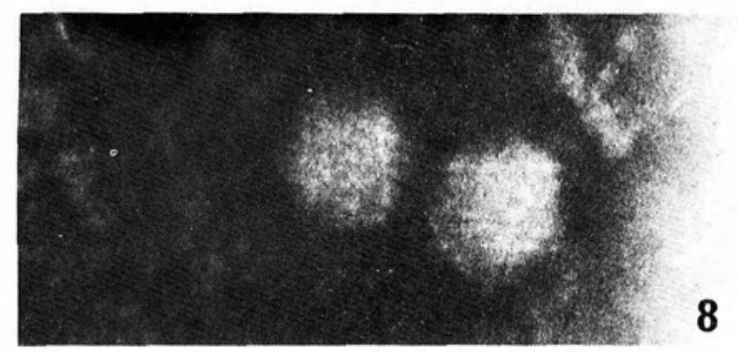

Fig. 8 Partículas romboidales de adenovirus en la tinción negativa del macerado del bazo. 250.000X.

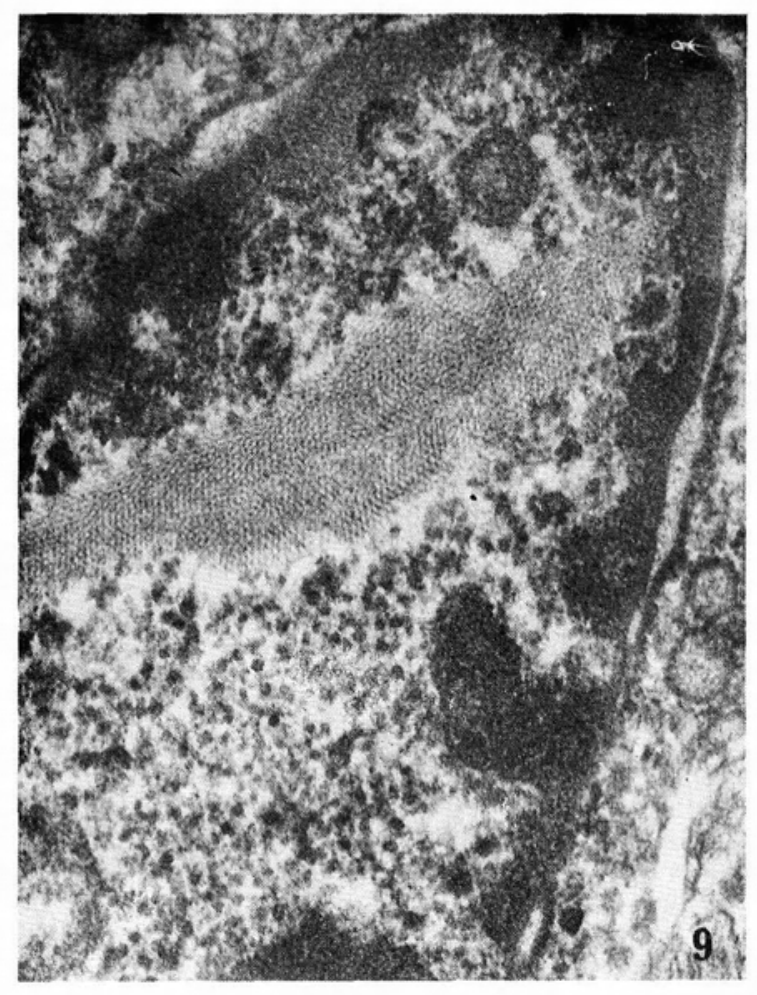

Fig. 9. Estructura cristalina filamentosa in tranuclear. 44.000X. 


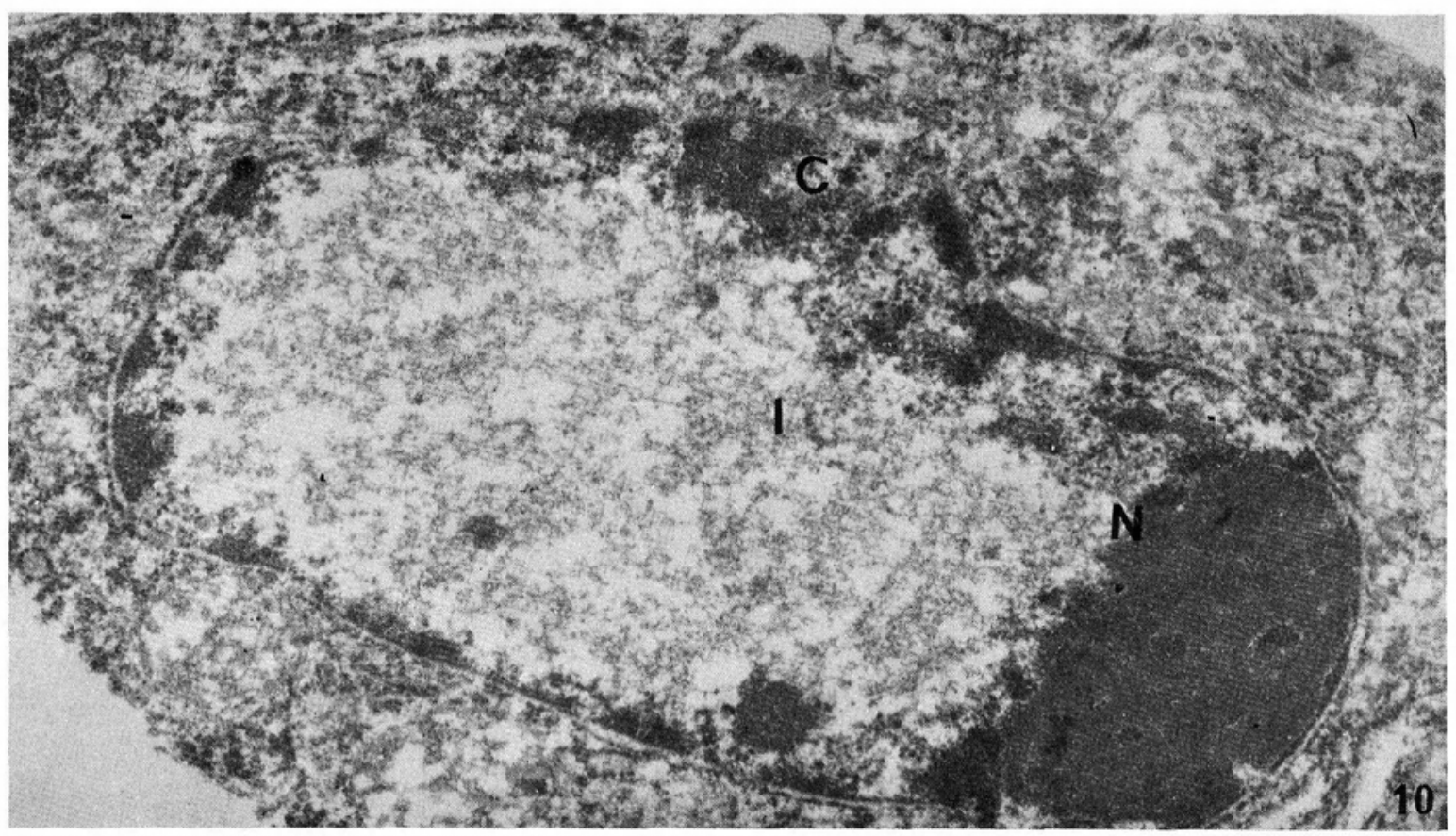

Fig. 10. Imagen clara filamentosa de la inclusión (I) en la fase inicial, C: cromatina densa marginada, N: estructura granular, posiblemente un nucleolo. Nótese que todavía no hay formación viral. 19600X.

En otros núcleos la condensación cromatínica sobre la membrana nuclear es muy definida, el núcleo está aumentando de tamaño y ocupado en su mayor parte por el material reticular y granular, dentro del cual comienzan a insinuarse cápsides y viriones que terminan por ocuparlo totalmente (Figuras 11-14). La imagen densa, grande, planoconveja, característica, que se ve en la inclusión al microscopio de luz corresponde a un acúmulo granular o amorfo, de densidad menor que la cromatina nuclear, que a veces la rodea o se insinua dentro de ella (Figuras 10,13). La preservación estructural no es satisfactoria para su análisis morfológico detallado, pero su aspecto sugiere un nucleolo condensado y rechazado también periféricamente por el desarrollo viral intranuclear. En algunos núcleos con desarrollo viral avanzado se ven imágenes periféricas de estructuras estriadas, densas, en zig-zag que a veces forman amplios acúmulos (Figuras 14-15).

Es común la presencia de virus aislados $o$ en grandes conglomerados cristalinos en el citoplasma de algunas células (Figuras $13,16,18)$.

Se puede ver que provienen del paso del virus por la membrana nuclear en algunos casos, (Figura 13) o de fragmentación y ruptura nuclear en otros (Figura17). No obstante, la formación viral intracitoplasmática no puede excluirse con certeza. Estos acúmulos virales citoplasmáticos pueden alcanzar gran tamaño y se ven como inclusiones al microscopio de luz. Otra explicación para su presencia en el citoplasma podría ser la fagocitosis por macrófagos de fragmentos de células desintegradas como consecuencia de la infección viral. Algunas inclusiones citoplasmáticas están rodeadas por membranas, mientras que otras parecen estar libres (Figuras 16,17).

En los grandes acúmulos cristalinos se pueden observar partículas densas, cápsides vacías y cápsides de escaso contenido denso (Figuras 14, 16, 19) que miden $70-80 \mathrm{~nm}$ de diámetro y tienen la morfología romboidal de los adenovirus (Figura 19). 

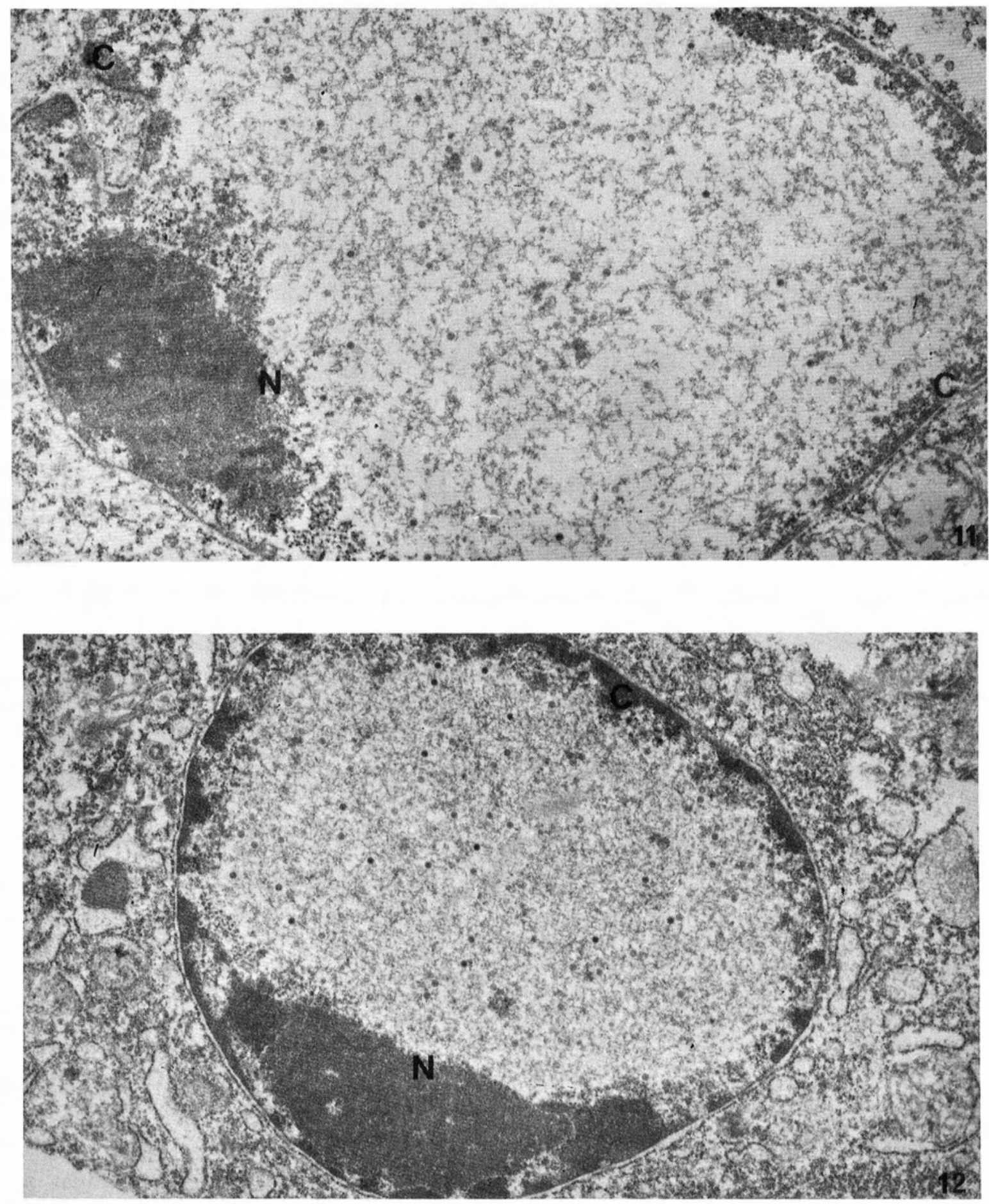

Figs. 11 y 12. Aparición de cápsides y viriones en la inclusión. C: cromatina densa sobre la membrana nuclear. $\mathrm{N}$ : nucléolo. 15.400X. 


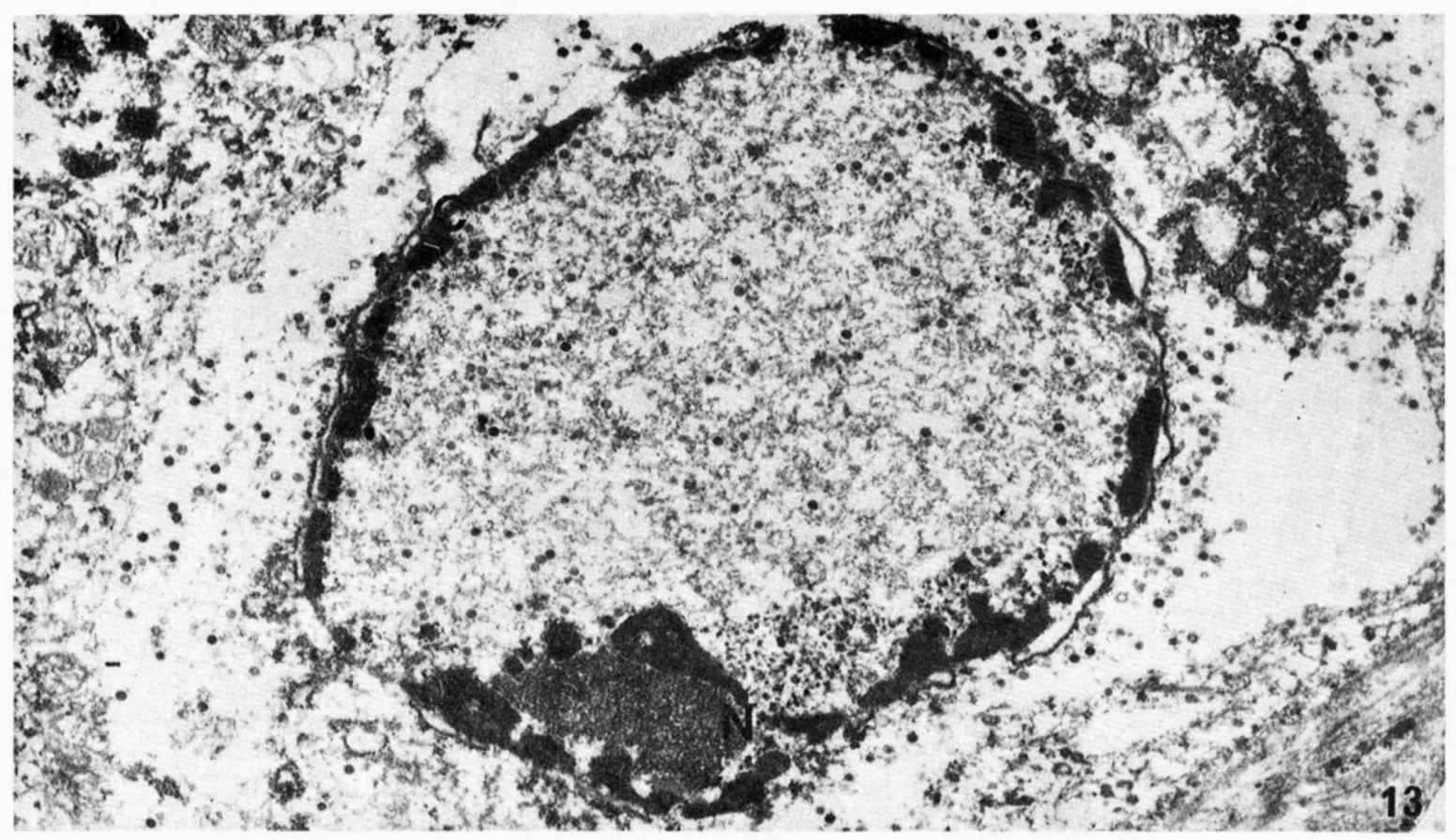

Fig. 13. Cápsides y viriones intranucleares e intracitoplasmáticos. C: cromatina. N: nucléolo. $16.000 \mathrm{X}$.

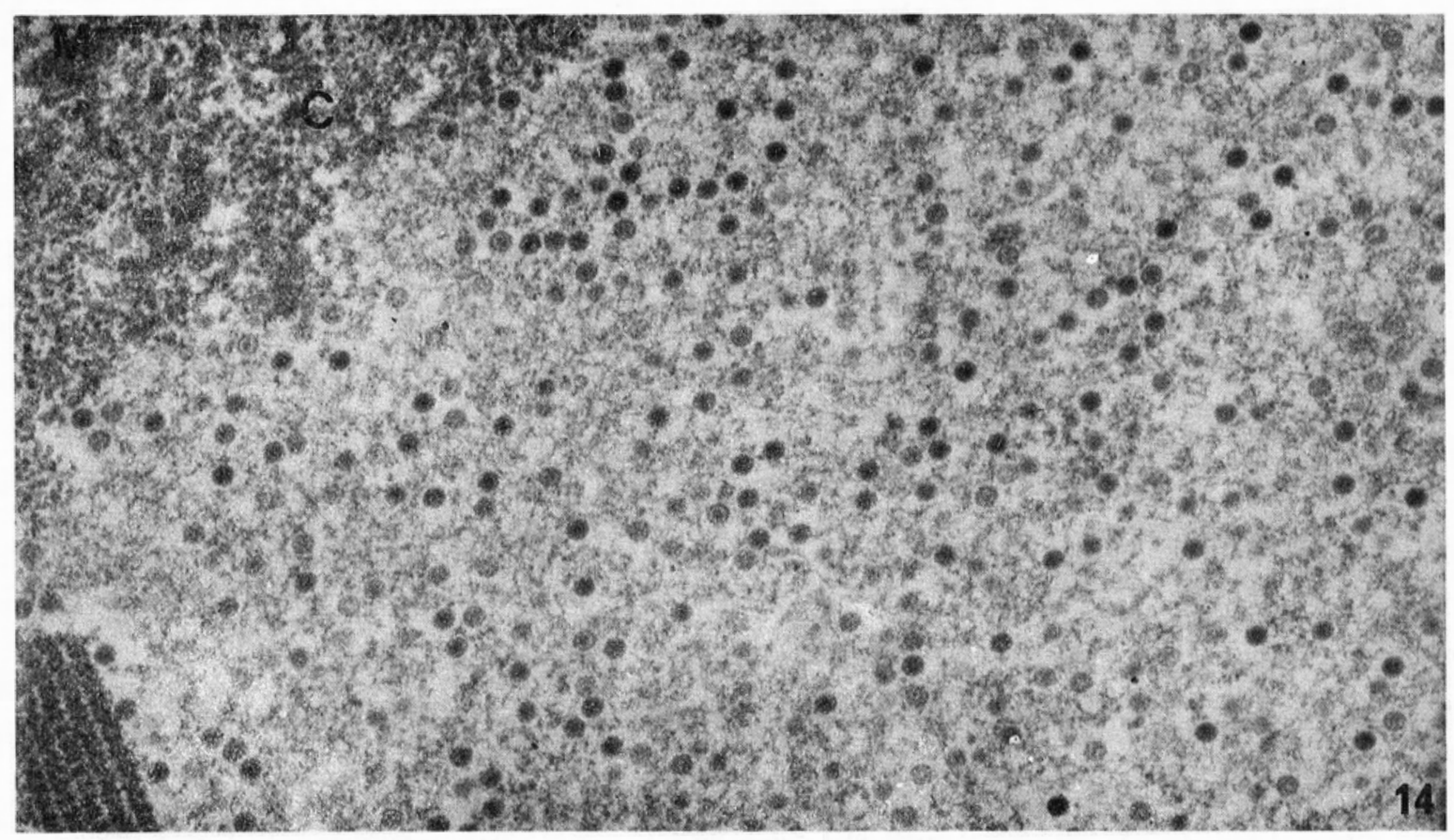

Fig. 14. Abundancia de viriones, cápsides y exceso de material filamentoso y granular en una inclusión "madura". Nótese el material estriado abajo, a la izquierda. C: cromatina. M: membrana nuclear. 33.600X. 


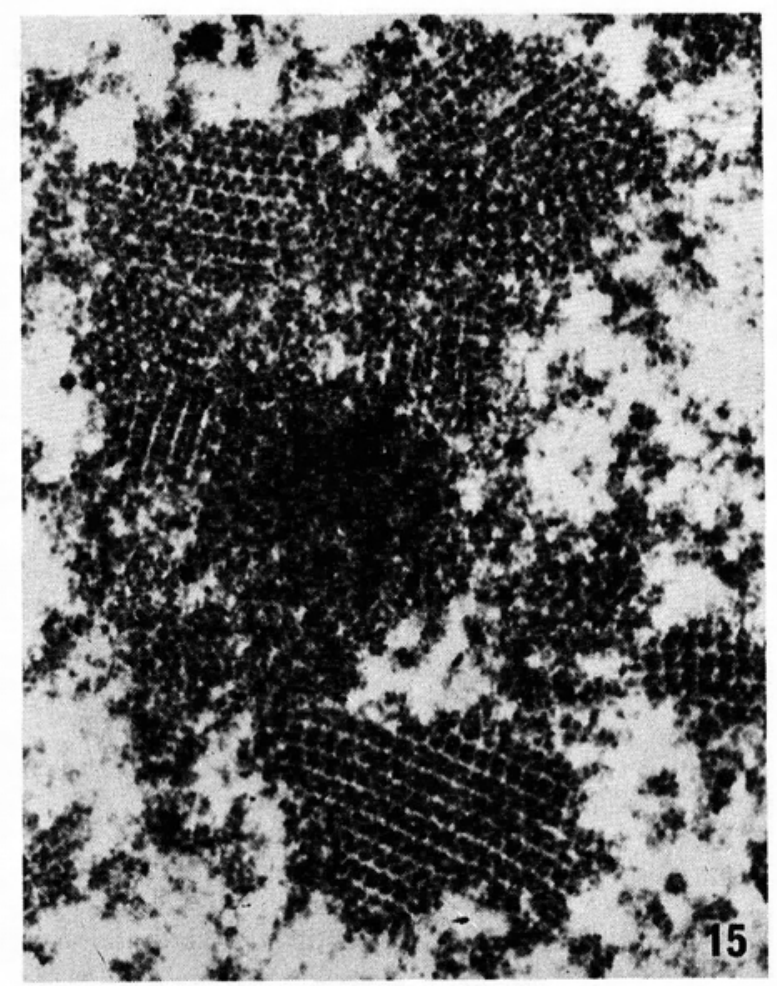

Fig. 15. Ampliación del material estriado de la figura 14. Probablemente represente exceso de antígeno viral. $36.000 \mathrm{X}$.

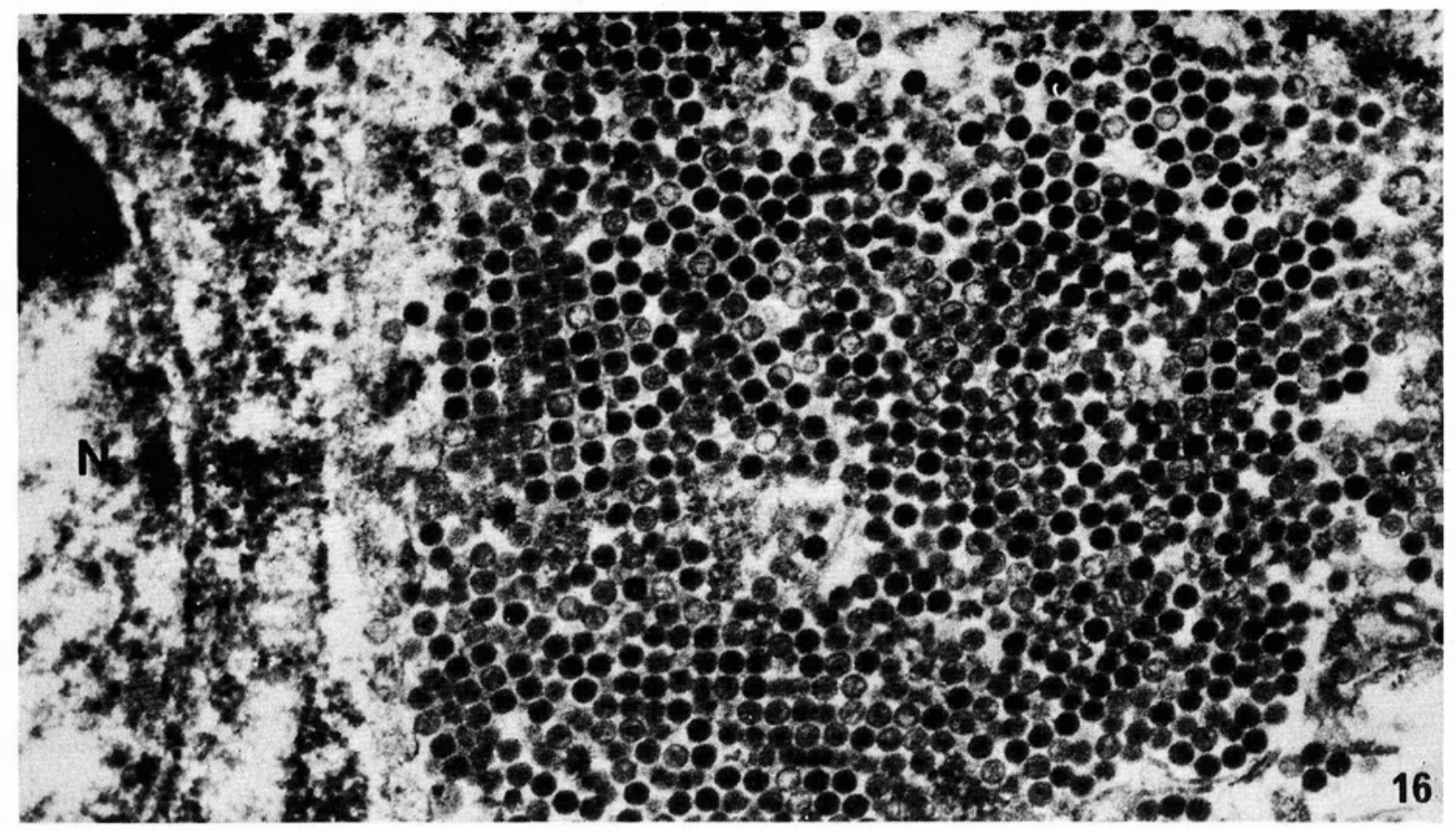

Fig. 16. Cristal de virus en el citoplasma. N: núcleo. 40.000X. 


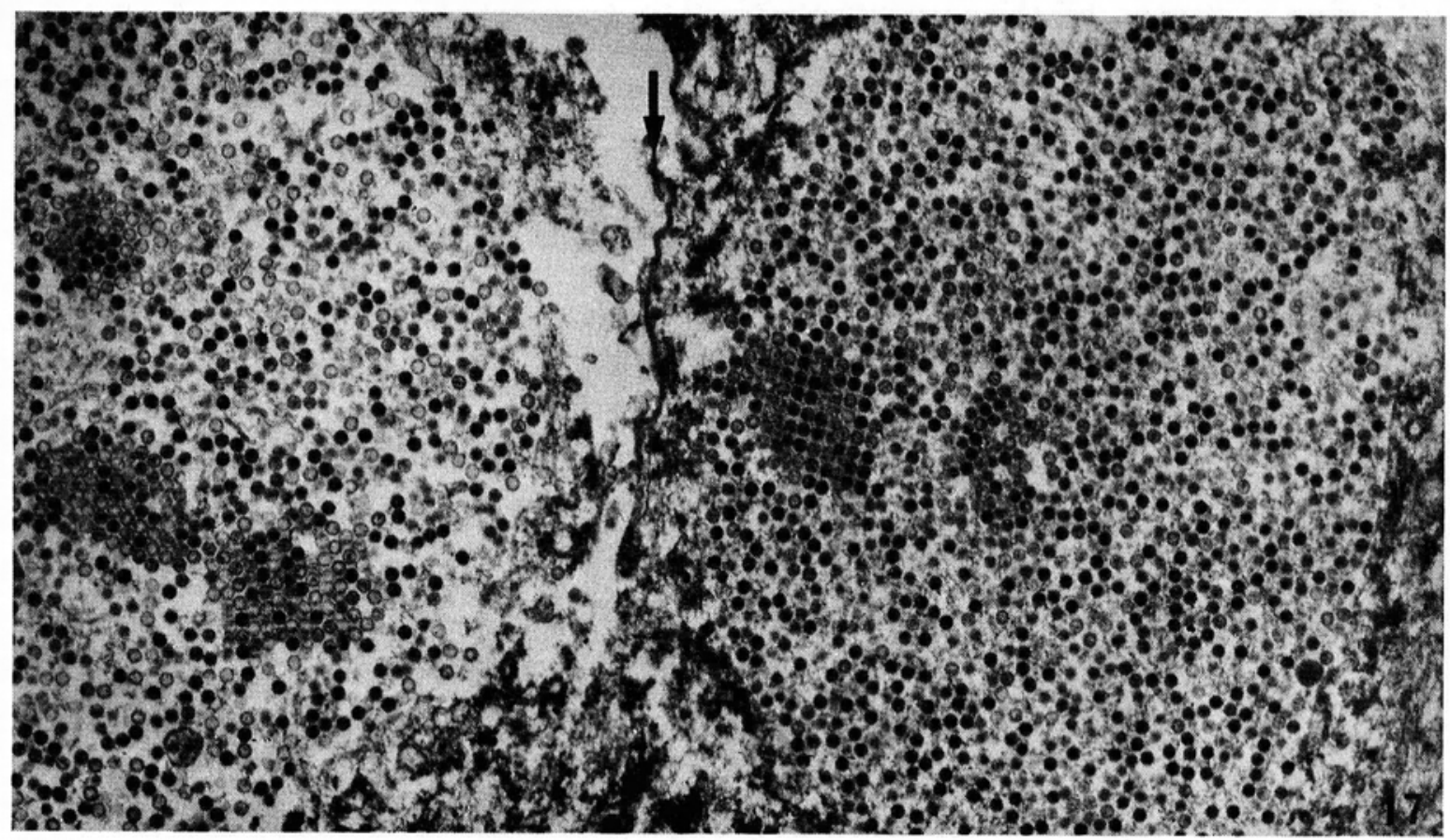

Fig. 17. Cristales de virus. La membrana central (flecha) sugiere ruptura de la membrana nuclear. 20.000X.

No prestamos atención especial a los cambios del citoplasma puesto que la fijación prolongada en formol tamponado no preserva idealmente este componente tan rico en membranas. No obstante, la mayoría de las células infectadas contienen abundante retículo endoplásmico granuloso (REG) y ribosomas libres, que sugieren su origen linfoide blástico, posiblemente B.

\section{DISCUSION}

El presente trabajo demuestra la existencia en Colombia de la EH por adenovirus y abre las posibilidades de nuevos estudios por métodos simples, que establezcan la magnitud del problema en el país.

La variación en las tasas de morbilidad y especialmente de la mortalidad, ha hecho que no se preste la atención necesaria al problema, puesto que ciertas cepas ocasionan muy baja mortalidad o la enfermedad es confundida con otras entidades que ocasionan mortalidades más altas, como las aflatoxicosis, otras micotoxinas y la coccidiosis $(1,2,5,6)$. Por otra parte, la morbilidad baja drásticamente aproximadamente 10 días después de la observación de la descarga hemorrágica por las heces $(3,6)$, lo cual hace que el avicultor piense que el problema tuvo una evolución favorable, máxime si ha utilizado algún medicamento generalmente con un diagnóstico equivocado.

La hemorragia intestinal y esplenomegalia unidas a las abundantes y características inclusiones intranucleares en el bazo y el intestino son suficientes para establecer el diagnóstico que la ME confirma plenamente al demostrar los adenovirus en los cortes o por tinción negativa.

Es interesante destacar la demostración de partículas virales mediante tinción negativa en el macerado de bazo previamente fijado en formol, lo cual se correlaciona con la abundancia de inclusiones al microscopio de luz y de viriones al microscopio electrónico. 


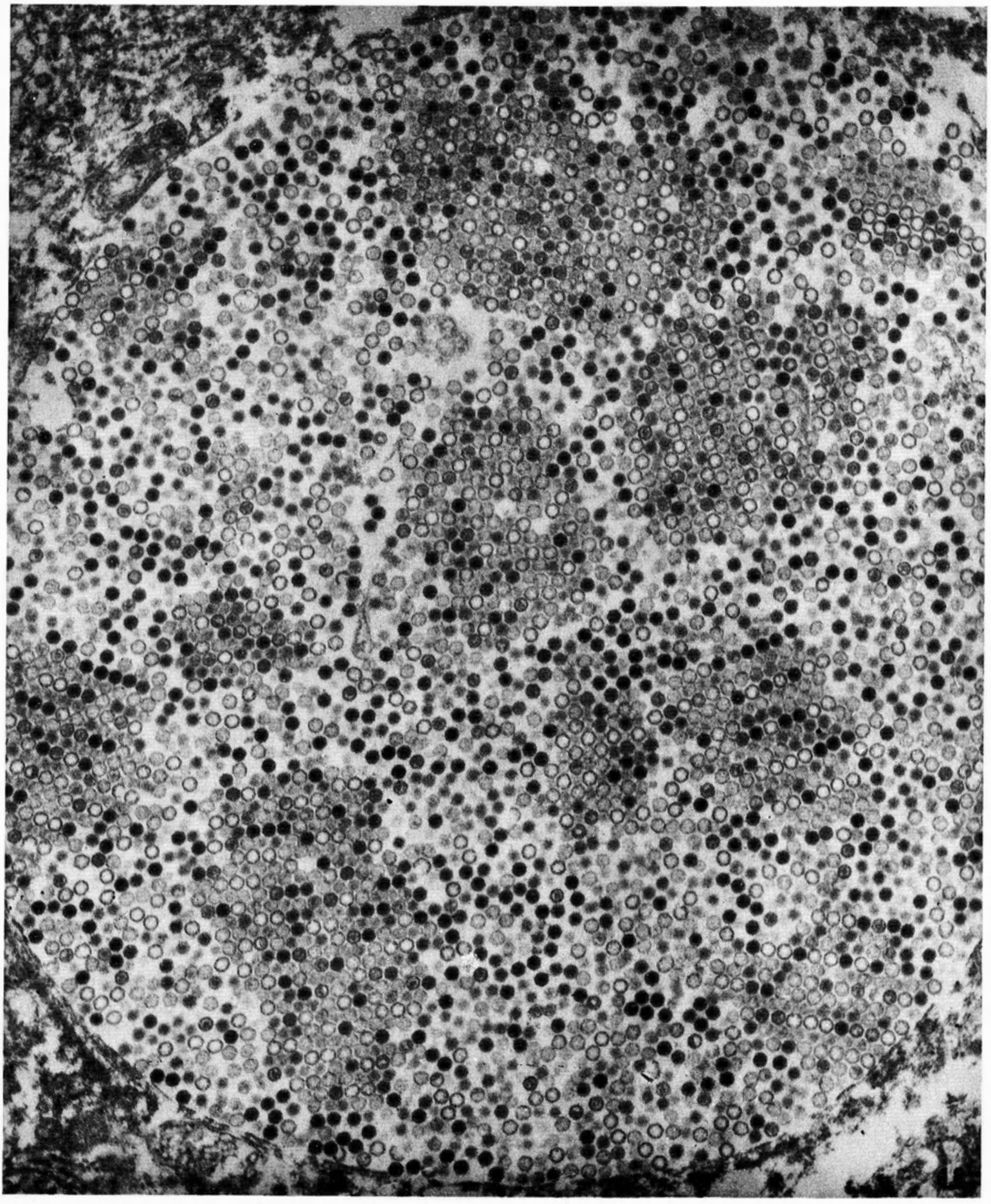

Fig. 18. Cápsides (partículas claras) y viriones (partículas densas), en una inclusión citoplasmática, rodeada por membrana. 36.000X. 


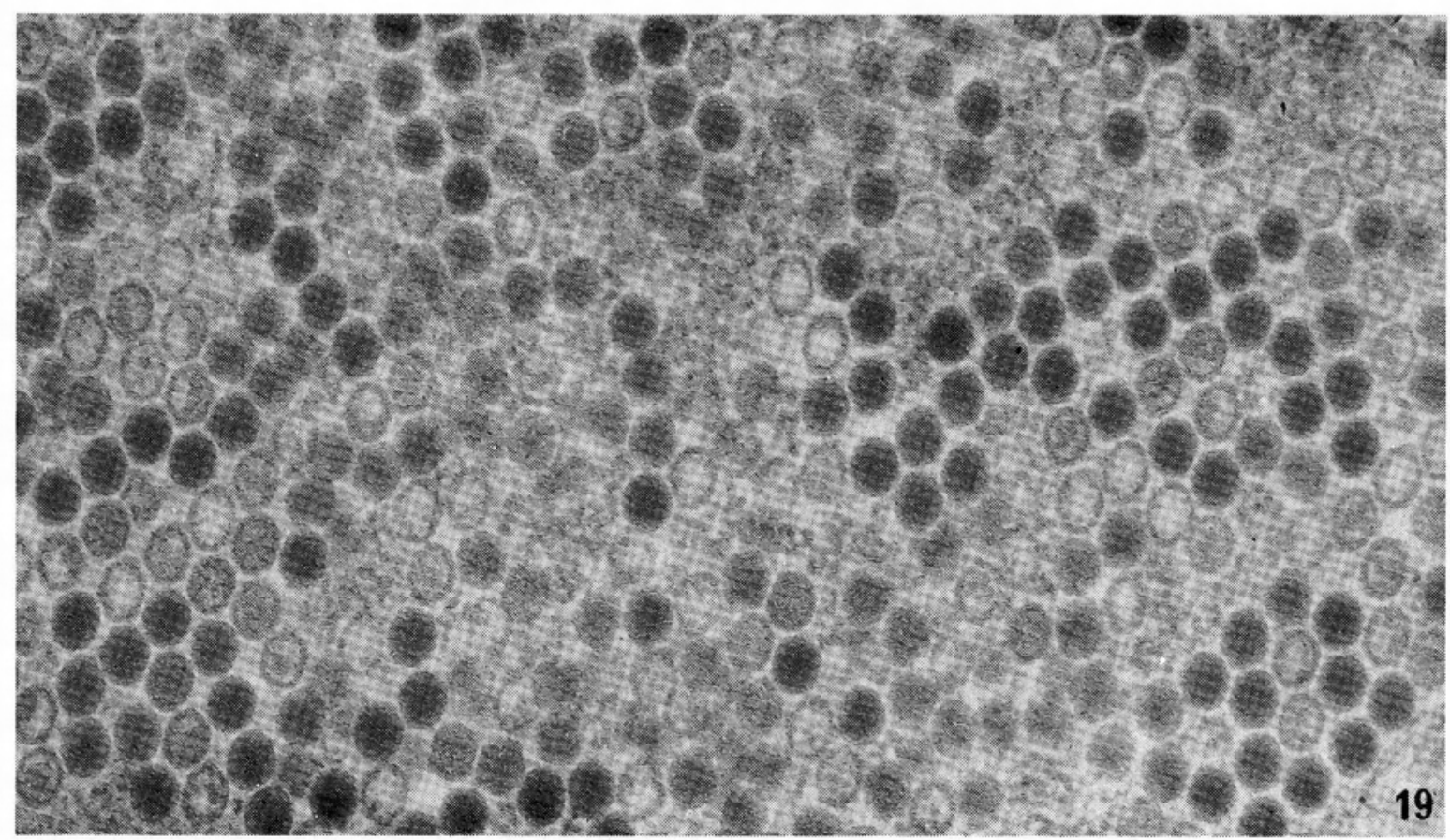

Fig. 19. Cápsides y viriones romboidales de una inclusión intranuclear. 75.000X.

No vimos las partículas virales en el macerado del contenido hemorrágico del intestino, posiblemente porque allí la concen tración viral no está en la cantidad de $10^{6}, 10^{9} / \mathrm{ml}$, necesaria para observarse al M.E.; el virus no se aplica en la mucosa intestinal y la eliminación de macrófagos llenos de virus a la luz intestinal es tal vez muy poca. Por eso el método de tinción negativa de heces, tan útil para el estudio de otras enteritis virales $(8,19,20,21)$, no lo es tanto para la presente entidad o a lo mejor exija realizar concentraciones prolongadas por ultracentrifugación. No obstante, es posible que la eliminación a la luz intestinal y la ruptura o excreción de histiocitos que contienen los viriones, sea la fuente de virus para las aves susceptibles.

La $\mathrm{EH}$ es una enfermedad grave y letal por las severas lesiones intestinales que ocasiona, las cuales no han podido ser explicadas satisfactoriamente, especulándose que podrían ser ocasionadas por una toxina (12) o por la acumulación excesiva de proteínas virales, las cuales pueden eventualmente alcanzar niveles tóxicos que ocasionarían la hemorragia intestinal con la subsecuente muerte del ave $(16,22)$. La esplenectomía (16) o la bursectomía química (13), previas a la infección viral experimental, previenen la aparición de la enteritis hemorrágica.

Varios investigadores afirman que el virus se replica en las células retículares $(2,4,6,7,12)$, pero no está claro que quieren decir por células reticulares, designación que si no se precisa puede ser demasiado general y ambigua, aplicada a por lo menos cuatro tipos de células (23). Las inclusiones en el bazo se ven en la mayoría de células de la pulpa blanca, con excepción de las endoteliales, eritrocitos, linfocitos y algunas periarteriales. Por esto pensamos que la mayor parte de los histiocitos y otros mononucleares de la línea linfoide, pueden estar comprometidos en la infección viral y por lo tanto el espectro de la infección en el bazo es muy amplia, en contraste con la observada en el intestino, en donde las inclusiones se ven células de tipo histiocitario. 
Con el presente estudio se caracteriza por primera vez en el país una nueva entidad patológica en la especie aviar, considerada hasta el presente como una enfermedad exótica. En relación con la morbilidad y mortalidad observadas en el presente estudio, la impresión general es que en nuestro medio, el agente etiológico no presenta las características graves descritas en otros países.

\section{HEMORRHAGIC ENTERITIS IN TURKEYS}

\section{SUMMARY}

Hemorrhagic enteritis (HE) in 4 to 11 weeks old turkeys is described by the first time in Colombia, based on gross, morphologic and electron microscopic studies. Sick animales presented enteritis and splenomegaly as the main findings. Mononuclear cells of the lamina propria of the small intestine presented intranuclear inclusion bodies. In the spleen these bodies were seen in most of the cells of white and red pulp. The inclusion bodies were slightly eosinophilic and the chromatin was displaced to the nuclear membrane. A basophilic round flattened body, displaced to a nuclear pole, suggested a nucleolus. Ultrastructural studies of the inclusion development from the initial appearance of a cristaloid material to the final formation of large amounts of capsids and virions are described. Negative staing of spleen macerates presented typical adenovirus particles but these particles were not detected in the intestinal content by the same technique.

\section{BIBLIOGRAFIA}

1. Bustos, M.F.; Mossos, A.N. Causas de mortalidad en un plantel de pavos comerciales. Revista ICA (En prensa), 1983.

2. Domermuth, Ch. and Gross, W.B. Hemorrhagic enteritis of turkeys. Isolation and identification of avian pathogens. American Association of Avian Pathologists. Second Edition, 1975, pp. 106-107.

3. Domermuth, Ch. and Gross, W.B. Hemorrhagic enteritis. Diseases of poultry. Seventh Edition, 1978, pp. 590-595.
4. McFerran, J.B.; Adair, B. McC. Avian adenovirus. A review. Avian Pathology, 1977. 6: 189.

5. Aghakn, S.M. Avian adenoviruses. The Veterinary Bulletin, 1974. 9: 531.

6. Beasley, J. N., and Wisdom, J. Studies on the pathogenesis of hemorrhagic enteritis of turkeys. Avian Diseases. 1978, 22: 313.

7. Carlson, H.C., and Fuad Al-Sheikhly. Virus particles in spleens and intestines of turkeys with hemorrhagic enteritis. Avian Diseases. 18: 67 .

8. Fenner, F.E., McAuslan, B.R.; Mims, C.A.; Sambrook, J. The biology of animal viruses, second edition. Academic Press, 1974, pp. 357-358.

9. King, W.D. Ultrastructural aspects of disease. Hoeber Medical Division. N.Y. Evanston and London. 1966, p. 52.

10. Fadly, A.M. and Nazerian, K. Efficacy and safety of cell culture live virus vaccine for hemorrhagic enteritis of turkeys. Laboratory studies, Avian Diseases. 1984, 128: 183.

11. Nazerian, K. and Fadly, A.M. Propagation of turkeys hemorrhagic enteritis virus in cell culture. Abstracts of the 118th Am. Vet. Med. Assoc. Meeting. 1981, : 19.

12. Gross, W.B. Lesions of hemorrhagic enteritis. Avian Diseases, 1967, 11: 684.

13. Fadly, A.M. and Nazerian, K. Evidence for bursal involment in the pathogenesis of hemorrhagic enteritis of turkeys. Avian Diseases. 1982, 26: 525.

14. Ianconescu, M.; Smith, E.J.; and Nazerian, K. An enzyme-linked immunosorbent assay for detection of hemorrhagic enteritis virus and associated antibodies. Avian Diseases. 1984, 28: 669 .

15. Veit, H.P.; Domermuth, C.H., and Gross, W.B. Histopathology of avian adenovirus Group II. Splenomegaly of chickens. Avian Diseases. 1981, 25: 866.

16. Ossa, J,E.; Alexander, J.; and Shuri, G.G. Role of splecnetomy in prevention of hemorrhagic enteritis and death from hemorrhagic enteritis virus in turkeys. Avian Diseases. 1983, 27: 1106 
17. Malkinson, M.; Weisman, J.; Aronovici, A.; Davidson, I. Hemorrhagic enteritis of turkeys. Comparison of two serological assays for detection antibodies in one day-old poults, sick and convalescent turkeys. Veterinary Record. 1983, 113: 497.

18. Thorsen, J.; Weniger, N.; Weber, L., and Vac Dijk. Field trials of an immunization procedure against hemorrhagic enteritis of turkeys. Avian Diseases. 1982, 26: 473.

19. Andral, B. et Toquin, D. Observations au microscope electronique a partir de prelevements de dindes presentant des troubles pathologiques. Avian Pathology. 1984, 13: 389.
20. McNulty, M.S.; Curran, W.L.; Tood, D. and McFerran, J.B. Detection of viruses in avian faeces by direct electron microscopy. Avian Pathology. 1979, 8: 239.

21. Rodríguez, G. Microscopía electrónica de la infección viral. Instituto Nacional de Salud, Bogotá, Colombia. 1983, pp. 165-183.

22. Velentine, R.C.; and Pereira, H.G. Antigens and structure of adenovirus. J. Mol. Biol. 1965, 13: 13.

23. Carl, I. The macrophage. A review of ultrastructure and function. Academic Press London. New York. 1973, ${ }_{7}$ p. 3-5. 